\title{
Morphologic features of the uniatrial but biventricular atrioventricular connection
}

Laszlo Kiraly, MD, FETCS, ${ }^{a}$ Martha Hubay, MD, ${ }^{\text {b }}$ Andrew C. Cook, BSc, PhD, ${ }^{c}$ Siew Yen Ho, BSc, PhD, ${ }^{d}$ and Robert H. Anderson, BSc, MD, FRCPath ${ }^{\mathrm{c}}$

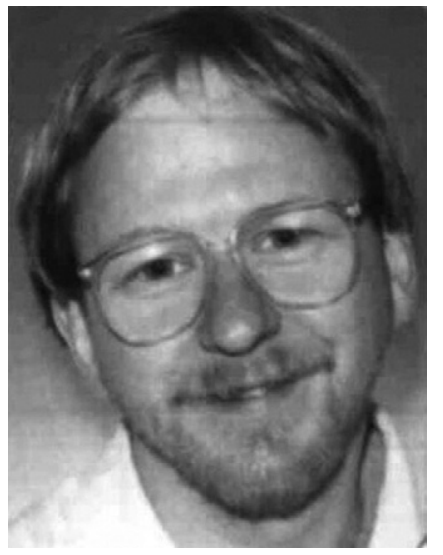

Dr Kiraly

丹 Supplemental material is available online.

From the Gottsegen Hungarian Institute of Cardiology, Pediatric Cardiac Centre, ${ }^{a}$ Budapest, Hungary; Department of Forensic Pathology, Semmelweis University, Budapest, Hungary; Institute of Child Health, Cardiac Unit, University College London, ${ }^{c}$ United Kingdom; and National Heart and Lung Institute Imperial College School of Medicine, ${ }^{\mathrm{d}}$ London, United Kingdom.

L. K., M. H., A. C. C., and R. H. A. were supported by a British-Hungarian Intergovernmental Science and Technology Cooperation Project with the sponsorship of the British Council Hungary (No. GB-41/2003, The Virtual Museum, R\&D Nos. $03 \mathrm{CC} 13$ and 02CC04). R. H. A. and A. C. C. are supported by the British Heart Foundation and the Joseph Levy Foundation.

Received for publication June 26, 2006; revisions received Aug 11, 2006; accepted for publication Aug 29, 2006.

Address for reprints: Laszlo Kiraly, MD, FETCS, Pediatric Cardiac Surgeon-In-Chief, Gottsegen Hungarian Institute of Cardiology, Pediatric Cardiac Centre, H-1450 Budapest, Pf. 88. H-1096 IX. Haller u. 29. Hungary (E-mail: kiraly@kardio.hu, kiralyl@hu.inter. net).

J Thorac Cardiovasc Surg 2007;133:229-34

$0022-5223 / \$ 32.00$

Copyright () 2007 by The American Association for Thoracic Surgery

doi:10.1016/j.jtcvs.2006.08.067
Objectives: Hearts with an absent atrioventricular connection and a straddling of the solitary atrioventricular valve are rare but significant lesions. They are suitable only for Fontan-like palliation, in which atrioventricular valvar abnormalities play a significant role in determining the outcome. We studied the segmental arrangements in such lesions and clarified the valvar morphology, particularly its surgical implications.

Methods: We made a macroscopic review of all specimens with an absent atrioventricular connection and a straddling atrioventricular valve that were held in the collections of 3 institutes. We included only those specimens with the straddling valve supported exclusively by either the right-sided or left-sided atrioventricular junction and excluded those with a common atrioventricular junction.

Results: We found 11 hearts with an absent right atrioventricular connection and a straddling left atrioventricular valve, and 3 with an absent left atrioventricular connection and a straddling right atrioventricular valve. Most had right-hand ventricular topology and discordant ventriculoarterial connections. We found multiple valvar abnormalities, including dysplastic leaflets, short cords, abnormal attachments, and abnormal papillary muscles. The most consistent features were a line of maximal coaptation between the bridging leaflets always perpendicular to the plane of the ventricular septum and a free-floating bridging anterosuperior leaflet.

Conclusions: Straddling of a solitary atrioventricular valve with an absent atrioventricular connection produces a uniatrial but biventricular connection. In this setting, the valve guarding the abnormal solitary atrioventricular junction cannot be classified morphologically as mitral or tricuspid. The markedly variable valvar morphology likely makes these valves prone to insufficiency in the long term.

$\mathrm{S}$ traddling of an atrioventricular (AV) valve when $1 \mathrm{AV}$ connection is absent is a rare but significant lesion. ${ }^{1}$ In this setting, the potential surgical options are unlikely to extend beyond creation of the Fontan circulation. ${ }^{2}$ Because $\mathrm{AV}$ valvar competency remains a key factor in the success of any Fontan-like palliation, it is important to know the underlying morphology of valves involved. ${ }^{3}$ In this context, the straddling AV valves seen with an absent AV connection can be found with various segmental arrangements. ${ }^{4,5}$ We undertook this study to demonstrate the different segmental arrangements and to search for any unifying morphologic features of morphology of the straddling valvar leaflets, their cordal attachments, and the arrangement of their papillary muscles relative to the supporting ventricular septal structures.

\section{Materials and Methods}

We restudied 14 specimens in which straddling and overriding of a solitary AV valve coexisted with the absence of $1 \mathrm{AV}$ connection. Of the specimens, 6 were from the archives of the Institute of Child Health, Cardiac Unit, University College London, United Kingdom; 5 were from the Royal Brompton Hospital, London, United Kingdom; and 3 were from 
Gottsegen Hungarian Institute of Cardiology, Pediatric Cardiac Centre, Budapest, Hungary. All series are historic, with the specimens being collected over periods spanning more than 35 years. Some of the hearts have been described. ${ }^{5}$

\section{Criteria for Inclusion and Definitions}

We included only those hearts with unequivocal absence of $1 \mathrm{AV}$ connection, the muscular floor of the atretic atrium being separated from the underlying ventricular mass by the fibrofatty tissue of the AV groove. We excluded hearts with common AV junctions and malalignment of the atrial septum.

Straddling is defined as a mode of AV connection, the tension apparatus of the abnormal AV valve being inserted on both sides of the ventricular septum. Overriding describes attachment of the AV junction to both ventricles. A valvar leaflet is a unit of the continuous skirt of tissue that hangs from each AV junction, and the line of coaptation between adjacent leaflets is the commissure. Left and right as applied to ventricles account for their morphology, based on the nature of the apical trabecular patterns. Patterns of ventricular topology are described in terms of the way that the palmar surfaces of the hands can be placed on the septal surface of the morphologically right ventricle such that the thumb lies in the inlet and the fingers point to the outlet, giving right-hand and left-hand ventricular topologies. ${ }^{6}$

\section{Results}

In all 14 specimens, there was the usual arrangement of the atrial chambers and bodily organs (solitus). In hearts with an absent right AV connection, the morphologically right atrium was as expected for "tricuspid atresia," with an obvious dimple in the blind-ending floor, irrespective of whether there was right-handed or left-handed topology of the ventricular mass. It was not possible to predict the ventricular topology simply by examining the structure of the right atrium. Similarly, in hearts with an absent left AV connection, the structure of the morphologically left atrium was as expected for "mitral atresia," irrespective of the arrangement of the ventricular mass. All of the specimens had an interatrial communication of considerable size, either a patent oval foramen or an atrial septal defect within the oval fossa (Figures 1 and E1).

In all specimens, there were 2 chambers within the ventricular mass. On the basis of their apical trabecular morphology, we found right-hand topology in 10 specimens, 7 with an absent right AV connection and 3 with an absent left AV connection. The larger ventricle, forming the cardiac apex, was nominated as the dominant ventricle. In 6 hearts, the left ventricle was dominant. Of the remainder, 3 had right ventricular dominance, whereas in the remaining 5 specimens the ventricles were of the same size. The numbers of specimens studied was small, so we were unable to establish any correlation between the size of the ventricles, the presence of right-hand or left-hand ventricular topology, and whether they coexisted with the absence of the left or right AV connections.

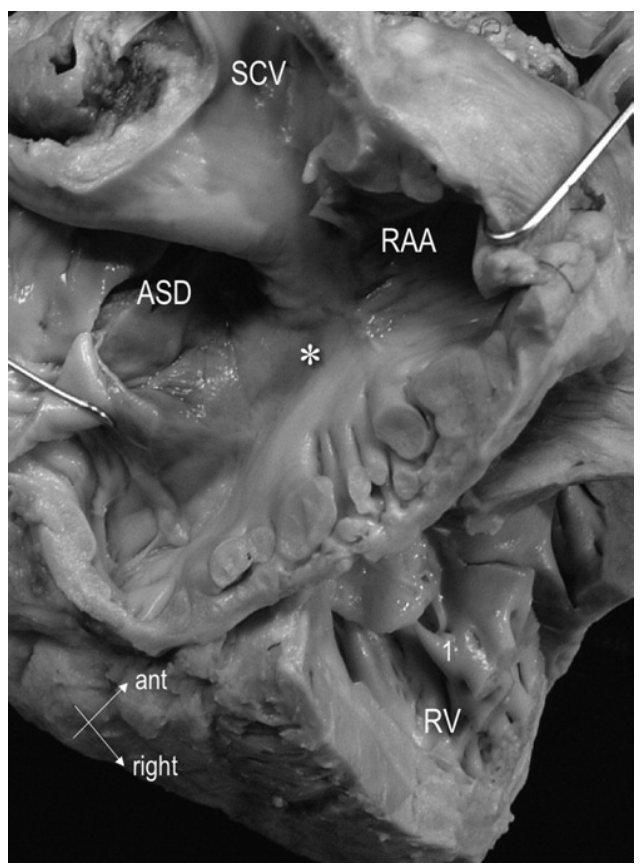

Figure 1. Absent right AV connection with straddling left AV valve. Specimen No. 6 is viewed through opening of the right atrium. Floor of the right atrium is blind $(*)$. 1: Papillary muscle anchors the straddling leaflet. $A S D$, Atrial septal defect; $R A A$, right atrial appendage; $R V$, right ventricle; $S C V$, superior caval vein.

\section{Absent Right Atrioventricular Connection With Straddling Left-sided Atrioventricular Valve}

Details of the segmental analysis of 11 specimens in this group are shown in Table 1.

We observed a full spectrum of the coexisting anomalies of the leaflets, cordal attachments, and papillary muscles in this group (Table 2).

The arrangement of the leaflets of the straddling leftsided valve was superficially reminiscent of the bridging leaflets seen in AV septal defect with a common AV junction, in that the anterosuperior leaflet was typically freefloating, whereas the posteroinferior leaflet more often had cordal attachments to the septum (Figures 2 and E2). In most instances, the bridging leaflets showed some degree of thickening or dysplasia. The principal line of coaptation of the bridging leaflets was always perpendicular to the plane of the ventricular septum. Short cords attached to the ventricular septum, often with imperforate tendinous attachments, combined with bulky papillary muscles frequently obstructed the communication with the smaller ventricle and/or the outflow tracts of either ventricle (Figures 3 and E3). In most specimens, the leaflets were supported by papillary muscles clustered in both the dominant and the smaller ventricle, although in one specimen the smaller 
TABLE 1. Segmental analysis of specimens with absent right atrioventricular connection and straddling left atrioventricular valve

\begin{tabular}{|c|c|c|c|c|c|c|c|c|}
\hline No. & $\begin{array}{c}\text { Ventricular } \\
\text { topology }\end{array}$ & $\begin{array}{l}\text { RV/LV } \\
\text { size }\end{array}$ & Override* & VSD & $\begin{array}{c}\text { Ventriculoarterial } \\
\text { connection }\end{array}$ & $\begin{array}{l}\text { Great artery } \\
\text { relationship }\end{array}$ & $\begin{array}{l}\text { Great artery } \\
\text { size }\end{array}$ & Remark \\
\hline 1 & I-hand & $75-25$ & $100-0$ & Inlet & DORV & Ao ant/left & $\mathrm{Ao}>\mathrm{PT}$ & \\
\hline 2 & I-hand & $66-33$ & $100-0$ & Inlet & DORV & Ao ant/left & $\mathrm{A}_{0}<\mathrm{PT}$ & \\
\hline 3 & I-hand & $50-50$ & $10-90$ & Inlet & DORV & Ao ant/left & $\mathrm{A}_{0}<\mathrm{PT}$ & \\
\hline 4 & I-hand & $50-50$ & $50-50$ & Inlet/outlet & DORV & Ao ant/left & $\mathrm{Ao}>\mathrm{PT}$ & \\
\hline 5 & r-hand & $50-50$ & $?$ & Inlet/outlet & $?$ & $?$ & $\mathrm{~A} 0>\mathrm{PT}$ & Sectioned for histology \\
\hline 6 & r-hand & $33-66$ & $25-75$ & Inlet/outlet & Conc & Sol & $\mathrm{A}_{0}=\mathrm{PT}$ & \\
\hline 7 & r-hand & $33-66$ & $0-100$ & Outlet & Disc & Ao ant/right & $\mathrm{A} 0=\mathrm{PT}$ & \\
\hline 8 & r-hand & $20-80$ & $10-90$ & Inlet/outlet & Disc & Ao ant/right & $\mathrm{A} 0<\mathrm{PT}$ & \\
\hline 9 & r-hand & $20-80$ & $?$ & $?$ & Conc & $?$ & $?$ & Sectioned for histology \\
\hline 10 & r-hand & $20-80$ & $0-100$ & Outlet & Disc & Ao ant/right & $\mathrm{A}_{0}<\mathrm{PT}$ & \\
\hline 11 & r-hand & $20-80$ & $0-100$ & Inlet/muscle & Disc & Ao ant & $\mathrm{Ao}>\mathrm{PT}$ & \\
\hline
\end{tabular}

$A$ o, Aorta; DORV, double-outlet right ventricle; $L V$, left ventricle; $P M$, papillary muscle; $P T$, pulmonary trunk; $R V$, right ventricle; $V S D$, ventricular septal defect; ?, impossible to determine because of state of specimen. *The AVV orifice overrides RV-LV.

ventricle lacked any papillary muscles (the straddling leaflets were directly attached to the free wall).

In the setting of left-hand ventricular topology, there was minimal malalignment between the planes of the atrial and ventricular septums, because the ventricular septum continued to extend to the crux of the heart. In those with righthand topology, there were varying degrees of malalignment; the extent of overriding and malalignment was parallel with the size of the smaller ventricle, although the correlation did not reach statistical significance (Figures 4 and E4). When each ventricle possessed its own outlet (in 6/11 cases), the smaller ventricle retained significant volume and was at least half the size of the dominant ventricle. In the other 5 cases, the smaller ventricle lacked any ventriculoarterial connection and was diminutive; this was associated with pulmonary atresia in 2 cases and obstruction to the systemic outflow in 3 cases ( 2 of which had interruption of the aortic arch).

\section{Absent Left Atrioventricular Connection With Straddling Right Atrioventricular Valve}

We found the combination of an absent left AV connection with a straddling right AV valve in 3 cases (Tables 3 and 4). All had right-hand topology of the ventricular mass with balanced ventricles. In all 3, there was gross malalignment between the planes of the atrial and ventricular septums. All had large and unrestrictive interventricular communications (Figures 5 and E5). The solitary valve, exclusively connected within the right atrium, had either 4 or 5 leaflets, with typically a free-floating anterosuperior bridging leaflet anchored by a single papillary muscle on each side of the ventricular septum. Superficially, these valves again bore a

TABLE 2. Valvar morphology in specimens with absent right atrioventricular connection and straddling left atrioventricular valve

\begin{tabular}{|c|c|c|c|c|c|c|c|}
\hline No. & $\begin{array}{l}\text { Total No. } \\
\text { of leaflets }\end{array}$ & $\begin{array}{l}\text { No. of leaflets } \\
\text { involved }\end{array}$ & $\begin{array}{c}\text { Leaflet } \\
\text { morphology }\end{array}$ & Tendinous cords & $\begin{array}{l}\text { Straddling leaflet } \\
\text { anchored onto }\end{array}$ & $\begin{array}{l}\text { PM in } \\
\text { RV-LV }\end{array}$ & $\begin{array}{c}\text { PM } \\
\text { morphology }\end{array}$ \\
\hline 1 & 4 & 2 & Dysplastic & Short & PM & $3-1^{*}$ & Cluster \\
\hline 2 & 3 & $?$ & & & $?$ & $?$ & $?$ \\
\hline 3 & 3 & 2 & Bridging leaflet† & Short/attached to free edge & VSD crest and PM & $3-1$ & Cluster \\
\hline 4 & 4 & 2 & Bridging leaflet & Short/attached to free edge & VSD crest and PM & $3-1$ & Cluster \\
\hline 5 & $?$ & $?$ & & & $?$ & $?$ & \\
\hline 6 & 4 & 2 & Dysplastic & Short & PM & $2-3$ & Cluster \\
\hline 7 & 4 & 1 & & Short & PM & $1-2$ & Muscle bar \\
\hline 8 & 5 & 2 & Bridging leaflet & Short & VSD crest and free wall & $0-2$ & Cluster \\
\hline 9 & $?$ & $?$ & & & $?$ & $?$ & \\
\hline 10 & 4 & 2 & Bridging leaflet & & PM & $1-2$ & Cluster \\
\hline 11 & 3 & 2 & Second orifice & Short & VSD crest and PM & $1-2$ & Cluster \\
\hline
\end{tabular}

$L V$, Left ventricle; $P M$, papillary muscle; $R V$, right ventricle; $V S D$, ventricular septal defect; ?, impossible to determine because of state of specimen. *Papillary muscles anchored in the dominant ventricle are marked bold. †Bridging leaflet: free-floating leaflet bridging over the ventricular septum. 


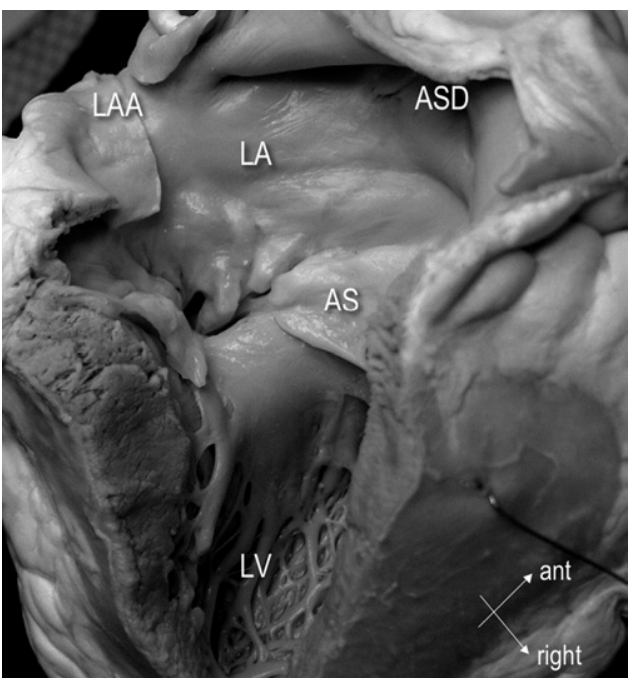

Figure 2. Absent right AV connection with straddling left AV valve; left-hand topology of the ventricles in specimen No. 4. Free-floating anterosuperior bridging leaflet is viewed through a left-posterior opening of the left atrium and left ventricle. ASD, Atrial septal defect; $L A$, left atrium; $L A A$, left atrial appendage; $L V$, left ventricle; $A S$, anterosuperior.

striking resemblance to those observed in AV septal defect with a common valvar orifice, but there was no mismatch between the inlet and outlet dimensions of the ventricular mass.

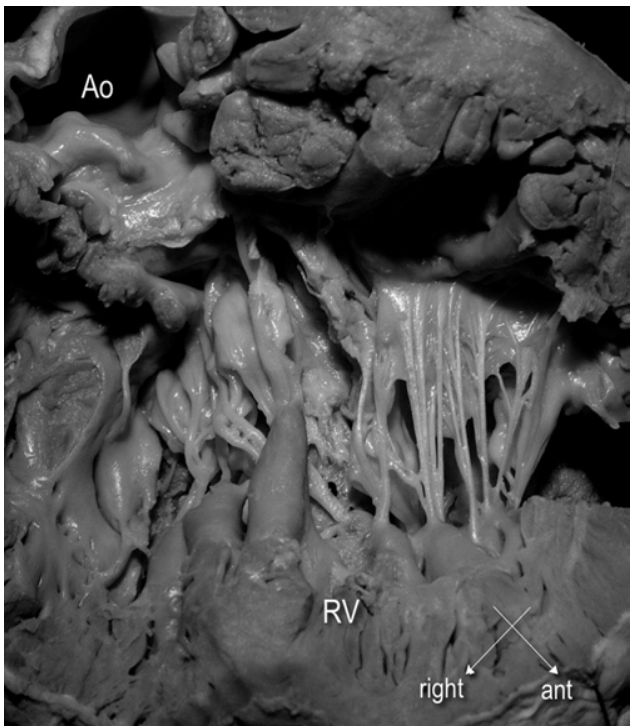

Figure 3. Absent right AV connection with straddling left AV valve without override; right-hand topology of the ventricles (specimen No. 10): Fused leaflets, short cords, and bulky papillary muscles represent an inflow impediment into the ventricle and between the dominant and smaller chambers. Ao, Aorta; RV, right ventricle.

\section{Discussion}

Functionally univentricular hearts account for the spectrum of cardiac malformations in which the ventricular mass is functionally univentricular; in other words, despite the presence of 2 ventricles, one or the other, for whatever reason, is incapable of supporting the systemic or pulmonary cir-

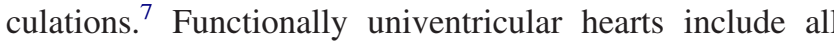
those hearts in which the atrial chambers connect to only 1 ventricle, that is, the hearts with univentricular AV connection, including those with a double-inlet AV connection and those with an absent AV connection. The group also includes the rarer hearts with biventricular AV connections that, in terms of physiology, are functionally univentricular. Also included in the overall group are the hearts addressed in this study, which possess uniatrial but biventricular AV connections.

There is striking similarity between the straddling valve found when $1 \mathrm{AV}$ connection is absent and the common AV valve found in the setting of an AV septal defect with a common AV junction. The obvious difference between the 2 lesions, however, is that the common AV valve guards a common AV junction. Such an arrangement is an anatomic impossibility when $1 \mathrm{AV}$ connection is absent. If we assess the situation in terms of development, then we recognize that a case can be made for a spectrum of malformation in which in the setting of gross malalignment of the atrial

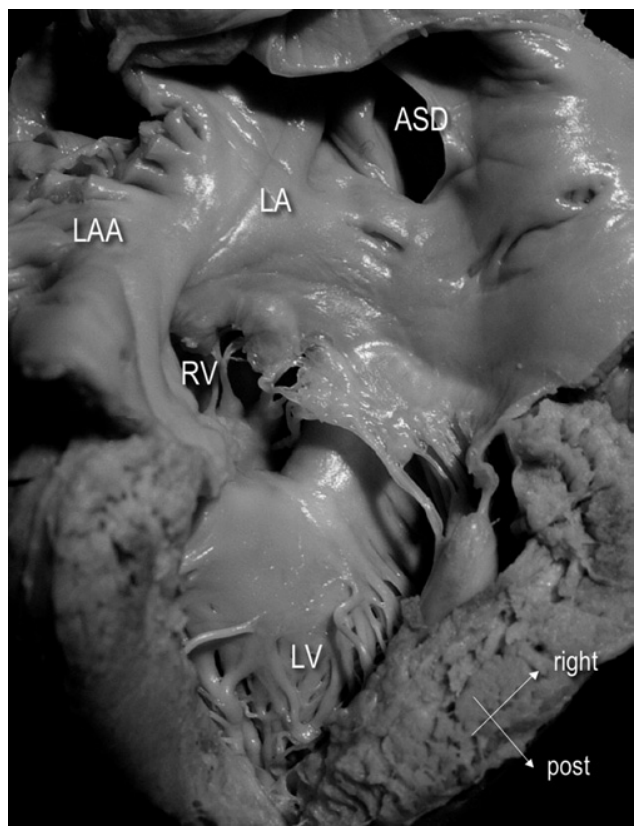

Figure 4. Absent right AV connection with straddling left AV valve; right-hand topology of the ventricles in specimen No. 8 viewed from the left through the left atrium and left ventricle. Note the gross malalignment of the atrial and ventricular septums. $A S D$, Atrial septal defect; $L A$, left atrium; $L A A$, left atrial appendage; $L V$, left ventricle; $R V$, right ventricle. 
TABLE 3. Segmental analysis of specimens with absent left atrioventricular connection and straddling right atrioventricular valve

\begin{tabular}{|c|c|c|c|c|c|c|c|c|}
\hline No. & $\begin{array}{l}\text { Ventricular } \\
\text { topology }\end{array}$ & $\begin{array}{l}\text { RV/LV } \\
\text { size }\end{array}$ & Override* & VSD & $\begin{array}{c}\text { Ventriculoarterial } \\
\text { connection }\end{array}$ & $\begin{array}{l}\text { Great artery } \\
\text { relationship }\end{array}$ & $\begin{array}{l}\text { Great artery } \\
\text { size }\end{array}$ & Remark \\
\hline 12 & r-hand & $60-40$ & $80-20$ & Inlet & DORV & Ao ant/right & $\mathrm{A}_{0}>\mathrm{PT}$ & \\
\hline 13 & r-hand & $50-50$ & $60-40$ & Inlet/outlet & Concordant & Ao post/left & $\mathrm{A}_{0}=\mathrm{PT}$ & \\
\hline 14 & r-hand & $50-50$ & $50-50$ & Inlet/muscle & DORV & Ao ant/right & $\mathrm{Ao}>\mathrm{PT}$ & PA \\
\hline
\end{tabular}

$A$ o, Aorta; $D O R V$, double-outlet right ventricle; $L V$, left ventricle; $P M$, papillary muscle; $P A$, pulmonary atresia; $P T$, pulmonary trunk; $R V$, right ventricle; $V S D$, ventricular septal defect. *AVV orifice overrides RV-LV.

septum, an "ostium primum" defect can become smaller and smaller until eventually the atrial septum fuses with the parietal AV junction, thus producing the absence of $1 \mathrm{AV}$ connection. In terms of the anatomy of the postnatal heart, however, the 2 situations remain unequivocally distinct, because there is either a common $\mathrm{AV}$ junction when the "primum" defect remains patent or a right or left AV junction when the primary atrial septum has fused with the AV junction. Despite the perceived similarities, straddling of the solitary AV valve is phenotypically distinct from the straddling common $\mathrm{AV}$ valve seen with gross malalignment between the atrial and ventricular septal structures. The difference is also of therapeutic significance, because it is well established that biventricular repair can be achieved in the setting of the common $\mathrm{AV}$ valve and malalignment of the atrial septum by reorientating the atrial septum with a patch placed to redirect the venous returns to their appropriate ventricles. Thus, although it is tempting to make an analogy between straddling of a solitary AV valve with coexisting AV valvar atresia, and the AV septal defect with gross septal malalignment (with both these phenotypic variants being described on occasion as forms of "double outlet atrium"), the marked difference in surgical options means that it is better to separate the 2 entities in terms of anatomy and classification.

It is generally acknowledged that in the Fontan circulation the competency of the AV valve plays a key role in keeping the preload pressures low and in preserving the ventricular function. The final outcome will inevitably be reduced when the AV valve restricts flow into or out of the ventricle, or should it become regurgitant. Irregular and dysplastic leaflets, short cords, fused attachments to the crest of the ventricular septum, and irregular papillary muscles, features observed in all the hearts we examined, present the anatomic basis for potential failure of the Fontan-type procedure because of the AV valvar abnormalities. After careful examination of our 14 specimens, we reached the conclusion that extensive repair would not have been feasible in the majority of the cases. Additional segmental and valvar anomalies were sufficient to have made biventricular repair equally impossible. We hypothesize that stitches placed to bring together the corresponding points of maximal opening of the leaflets, comparable to the edge-toedge repair described by Alfieri and colleagues, ${ }^{8}$ would restrict valvar insufficiency by creating a double orifice. Alternatively, the enlarged circumference of the AV orifice may permit a replacement of the AV valve with an oversized prosthesis. The frequent shallowness of the crest of the ventricular septum nonetheless may present additional problems of restricted motion of the leaflets of a prosthetic valve.

A dysfunctional and severely dysmorphic AV valve in the setting of other more common forms of functionally univentricular hearts has important implications for the success of the Fontan circulation. Analogies from this study can be applied to these more common situations, namely, that although repair of a dysfunctioning AV valve should always be attempted, it may not always be possible.

From the stance of morphology, the question arises as to whether the straddling and overriding valves can be classified as "mitral" or "tricuspid," with the so-existing atrial atresia then classified as "tricuspid" or "mitral." It might be thought that the morphology of the valve can be determined

TABLE 4. Valvar morphology in specimens with absent left atrioventricular connection and straddling right atrioventricular valve

\begin{tabular}{|c|c|c|c|c|c|c|c|}
\hline No. & $\begin{array}{l}\text { Total No. } \\
\text { of leaflets }\end{array}$ & $\begin{array}{l}\text { No. of leaflets } \\
\text { involved }\end{array}$ & Leaflet morphology & $\begin{array}{l}\text { Tendinous } \\
\text { cords }\end{array}$ & $\begin{array}{c}\text { Straddling leaflet anchored } \\
\text { onto }\end{array}$ & $\begin{array}{l}\text { PM in } \\
R V-L V\end{array}$ & PM morphology \\
\hline 12 & 5 & 2 & & Short & PM, septal crest & $2-1^{*}$ & Normal \\
\hline 13 & 4 & 2 & Bridging leaflet† & & PM, septal crest & $1-1$ & Muscle bar extending to leaflet \\
\hline 14 & 5 & 3 & Thickened bridging leaflet & Short & PM, free wall, septal crest & $1-1$ & Cluster \\
\hline
\end{tabular}

$\mathrm{LV}$, Left ventricle; $P M$, papillary muscle; $R V$, right ventricle; $V S D$, ventricular septal defect. *Papillary muscles anchored in the dominant ventricle are marked bold. $\dagger$ Bridging leaflet: free-floating leaflet bridging over the ventricular septum. 


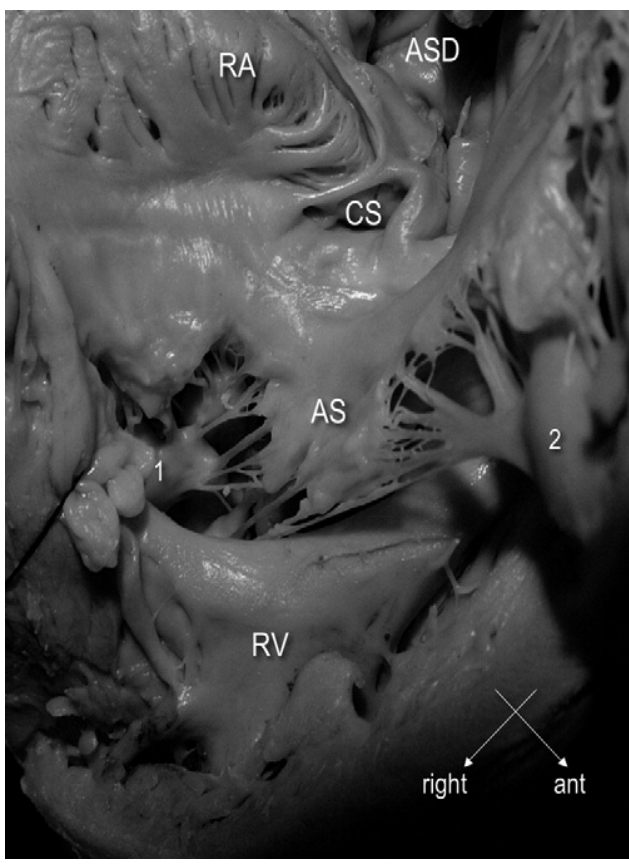

Figure 5. Absent left AV connection with straddling right AV valve; right-hand topology of the ventricles (specimen No. 14): Free-floating anterosuperior bridging leaflet is attached by short, muscularized cords to a papillary muscle $(1,2)$ in either ventricle. $A S D$, Atrial septal defect; $C S$, coronary sinus; $R A$, right atrium; $R V$, right ventricle; $A S$, anterosuperior.

according to the number of leaflets. It is known, however, that even in normal hearts the number of leaflets is unreliable as an arbiter of morphology and that cordal attachments are extremely variable. ${ }^{10-12}$ In hearts with biventricular AV junctions, when 1 single leaflet straddles the ventricular septum, features are still present that permit the valve involved to be identified as mitral or tricuspid., ${ }^{2,10}$ Our experience as described in this review shows that this is not possible when the straddling valve coexists with the absence of $1 \mathrm{AV}$ junction. The most consistent feature of the abnormal valves was the finding of the line of maximal coaptation between the bridging leaflets perpendicular to ventricular septum. This did not permit distinction of the valves as mitral or tricuspid. Thus, in this abnormal setting, with the arrangement of the atrial chambers defined, it makes most sense simply to describe the sides of the absent connection and the straddling valve. We believe this has important implications for the analysis of hearts with complex arrangements of the AV junctions, in which it is essential to describe both segmental topologies, junctional connections, and AV valvar morphology.

\section{References}

1. Milo S, Ho SY, Macartney FJ, Wilkinson JL, Becker AE, Gittenberger-de Groot AC, et al. Straddling and overriding atrioventricular valves: morphology and classification. Am J Cardiol. 1979;44:112234.

2. Anderson RH, Ho SY. Which hearts are unsuitable for biventricular correction? Ann Thorac Surg. 1998;66:621-6.

3. Caspi JC, Coles JG, Rabinovich M, Cohen D, Trusler GA, Williams WG, et al. Morphological findings contributing to a failed Fontan procedure. Circulation. 1990;82(Suppl IV):IV-177-82.

4. Wenink AC, Gittenberger-de Groot AC. Straddling mitral and tricuspid valves: morphologic differences and developmental backgrounds. Am J Cardiol. 1982;49:1959-71.

5. Ho SY, Milo S, Anderson RH, Macartney FJ, Goodwin A, Becker AE, et al. Straddling atrioventricular valve with absent atrioventricular connection. Report of 10 cases. Br Heart J. 1982;47:344-52.

6. Wilcox BR, Cook AC, Anderson RH. Analytic description of congenitally malformed hearts. In: Wilcox BR, Cook AC, Anderson RH, eds. Surgical Anatomy of the Heart. 3rd ed. Cambridge: Cambridge University Press; 2004:126

7. Jacobs ML, Anderson RH. Nomenclature of the functionally univentricular heart. Cardiol Young. 2006;16(Suppl 1):3-8.

8. Alfieri O, Maisano F, DeBonis M, Stefano PL, Torracca L, Oppizzi M, et al. The double orifice technique in mitral valve repair: a simple solution for complex problems. J Thorac Cardiovasc Surg. 2001;122: 674-81.

9. Pessotto R, Padalino M, Rubino M, Kadoba K, Büchler JR, Van Praagh R. Straddling tricuspid valve as a sign of ventriculoatrial malalignment: a morphometric study of 19 postmortem cases. $\mathrm{Am}$ Heart J. 1999;138:1184-95.

10. Sutton JP, Ho SY, Vogel M, Anderson RH. Is the morphologically right atrioventricular valve tricuspid? J Heart Valve Dis. 1995;4:571-5.

11. Victor S, Nayak VM. Variations in the papillary muscles of the normal mitral valve and their surgical relevance. J Card Surg. 1995;10:597607.

12. Frater RWM. Editorial: is the right sided atrioventricular valve trileaflet? J Heart Valve Dis. 1995;4:458-70. 

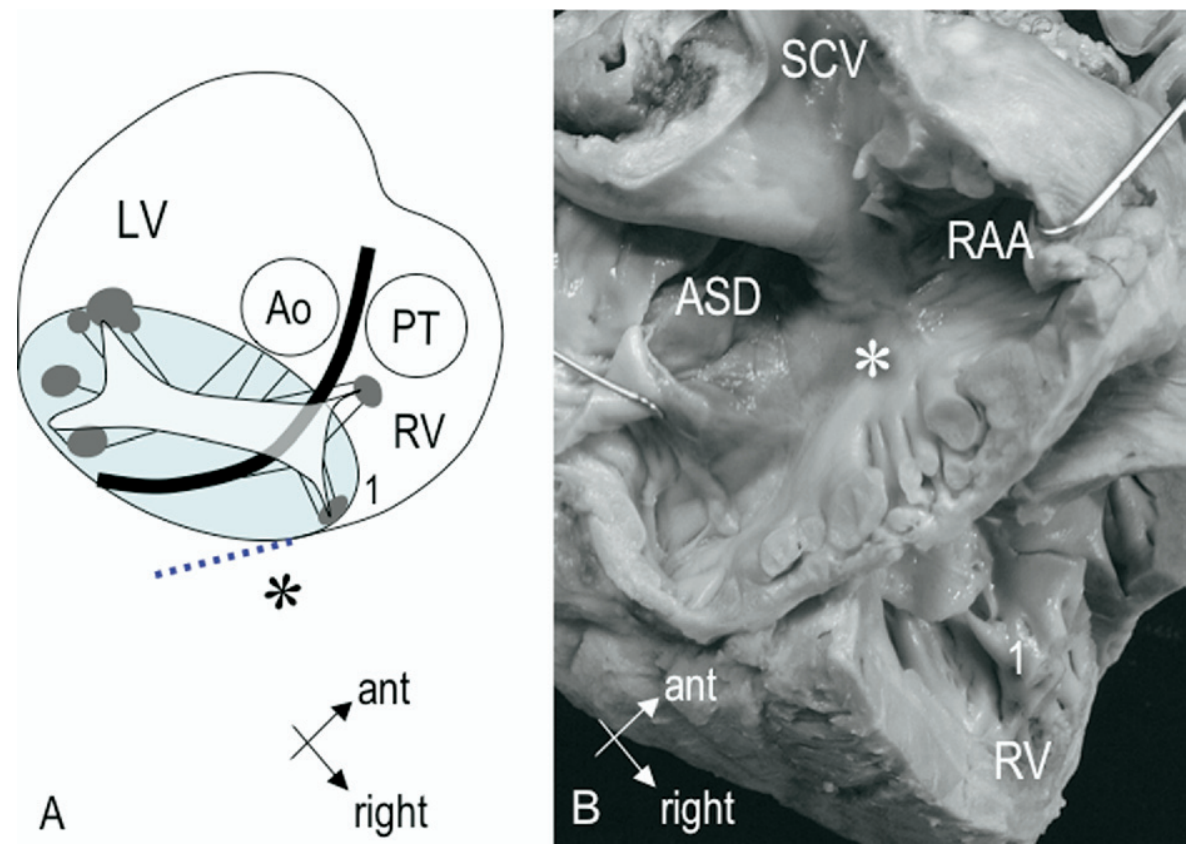

Figure E1. A, Segmental arrangement of specimen No. 6: absent right AV connection $\left({ }^{*}\right)$ with straddling left AV valve and gross malalignment of the atrial (dotted line) and ventricular (black line) septums. 1: Papillary muscle anchors the straddling leaflet. All diagrams correspond in projection to their respective photographs. $B$, The same specimen viewed through an opening of the right atrium. Floor of the right atrium is blind $(*)$. Ao, Aorta; $A S D$, atrial septal defect; $L V$, left ventricle; $P T$, pulmonary trunk; $R A A$, right atrial appendage; $R V$, right ventricle; $S C V$, superior caval vein. 

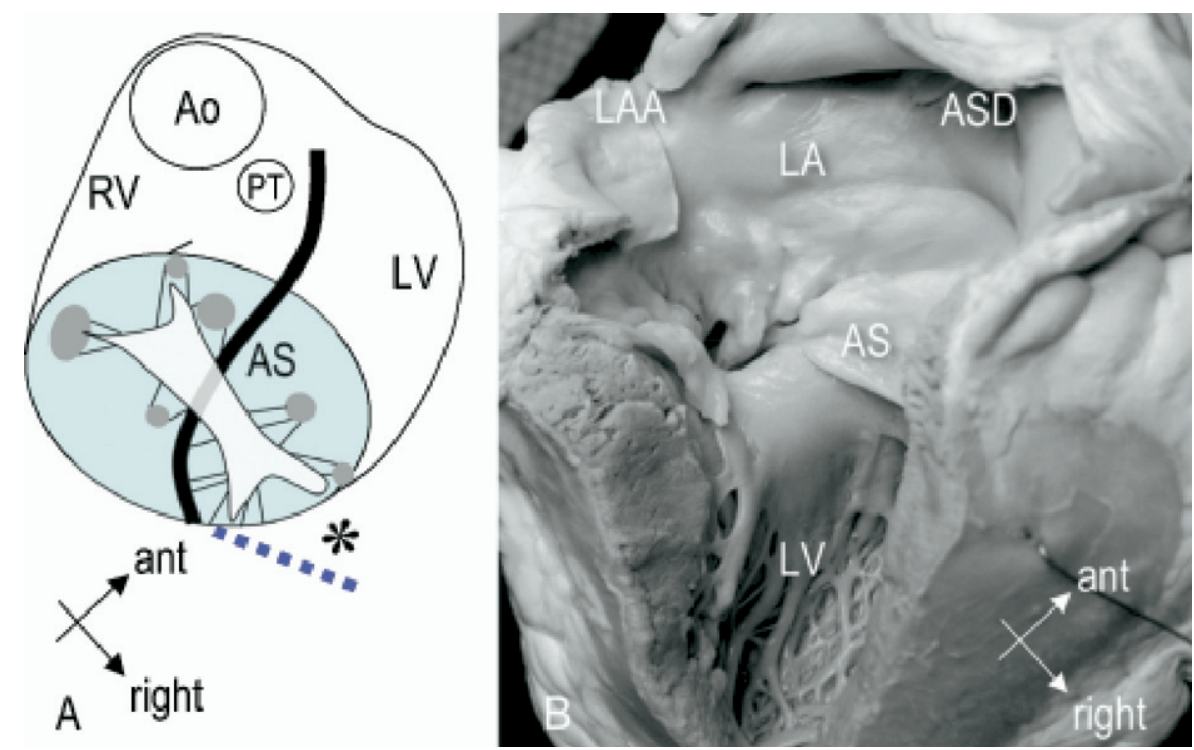

Figure E2. A, Segmental arrangement of specimen No. 4: absent right AV connection $\left({ }^{*}\right)$ with straddling left AV valve; left-hand topology of the ventricles; planes of the atrial (dotted line) and ventricular (black line) septums. Diagram corresponds in projection to its respective photograph. B, Free-floating anterosuperior bridging leaflet (AS) is viewed through a left-posterior opening of the left atrium and left ventricle. Ao, Aorta; ASD, atrial septal defect; $L A$, left atrium; $L A A$, left atrial appendage; $L V$, left ventricle; $P T$, pulmonary trunk; $R V$, right ventricle.
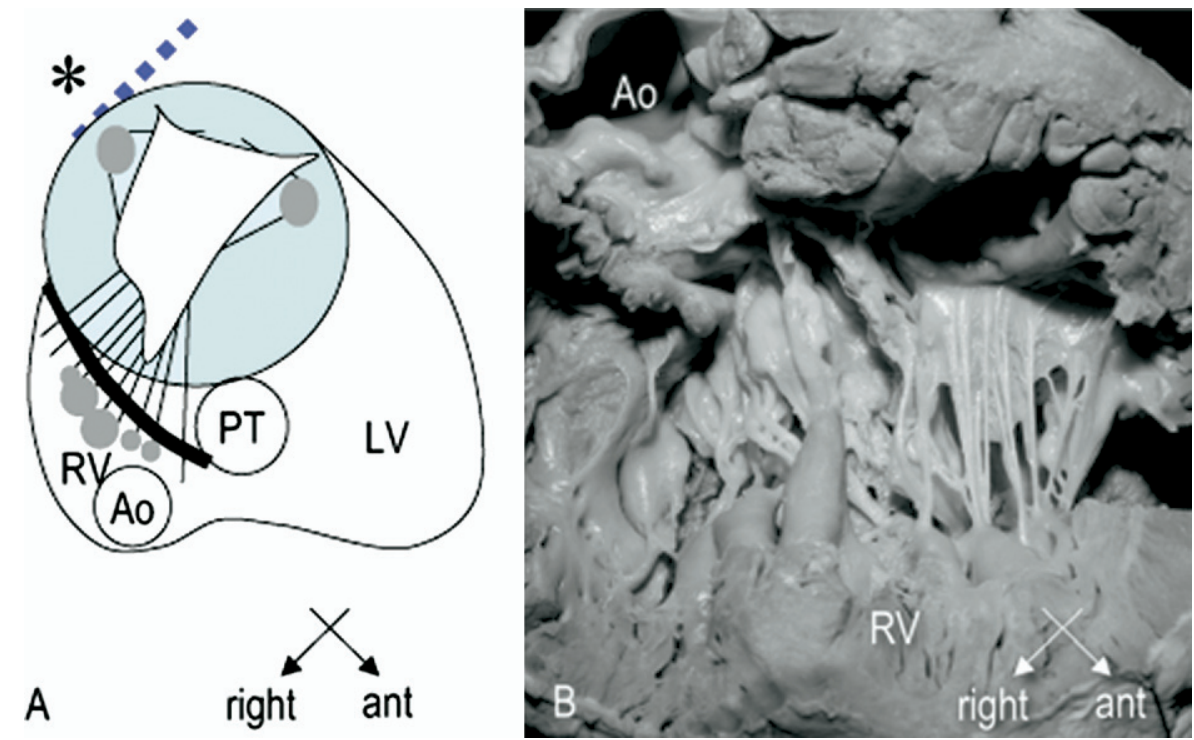

Figure E3. A, Segmental arrangement of specimen No. 10: absent right AV connection (*) with straddling left AV valve without override; right-hand topology of the ventricles; planes of the atrial (dotted line) and ventricular (black line) septums. Diagram corresponds in projection to its respective photograph. B, Fused leaflets, short cords, and bulky papillary muscles represent an inflow impediment into the ventricle and between the dominant and smaller chambers. Ao, Aorta; LV, left ventricle; PT, pulmonary trunk; RV, right ventricle. 


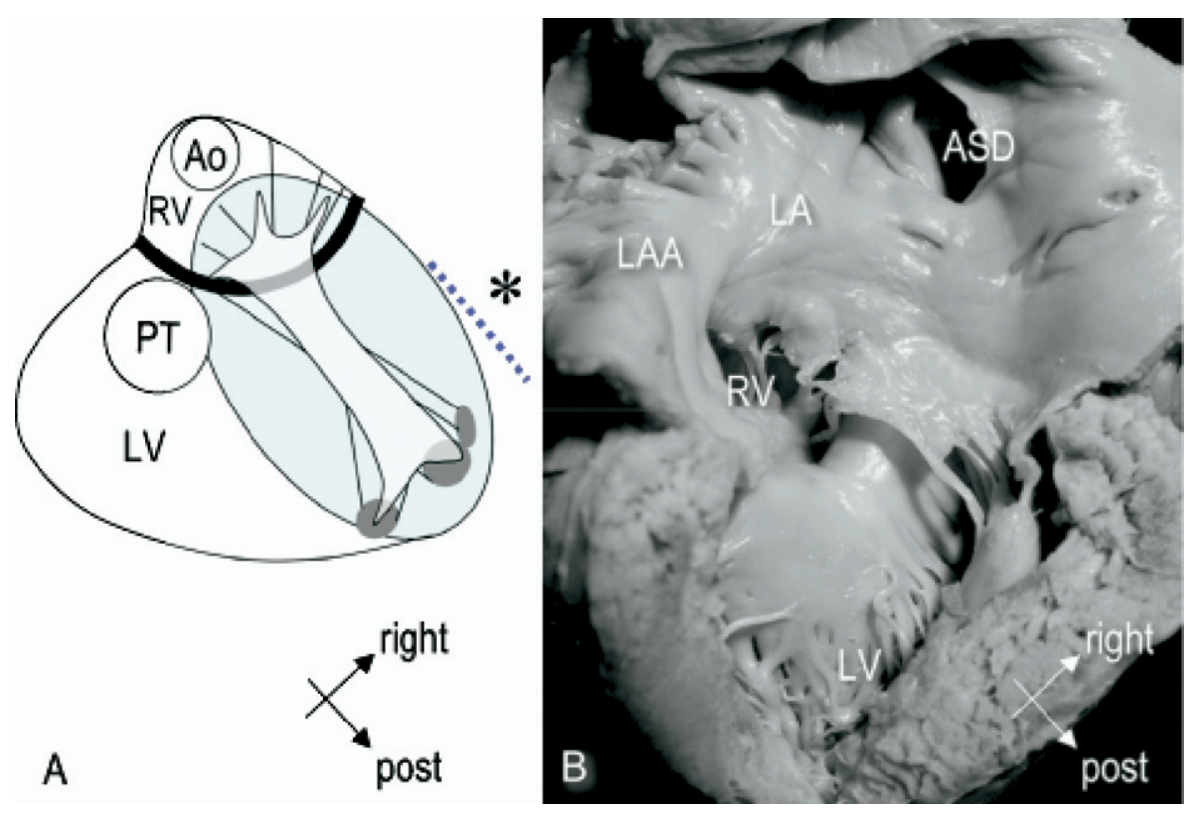

Figure E4. A, Segmental arrangement of specimen No. 8: absent right AV connection $\left({ }^{*}\right)$ with straddling left AV valve; right-hand topology of the ventricles; planes of the atrial (dotted line) and ventricular (black line) septums. Diagram corresponds in projection to its respective photograph. B, The same specimen, viewed from the left through the left atrium and left ventricle. Note the gross malalignment of the atrial and ventricular septums. Ao, Aorta; $A S D$, atrial septal defect; $L A$, left atrium; $L A A$, left atrial appendage; $L V$, left ventricle; $P T$, pulmonary trunk; $R V$, right ventricle. 


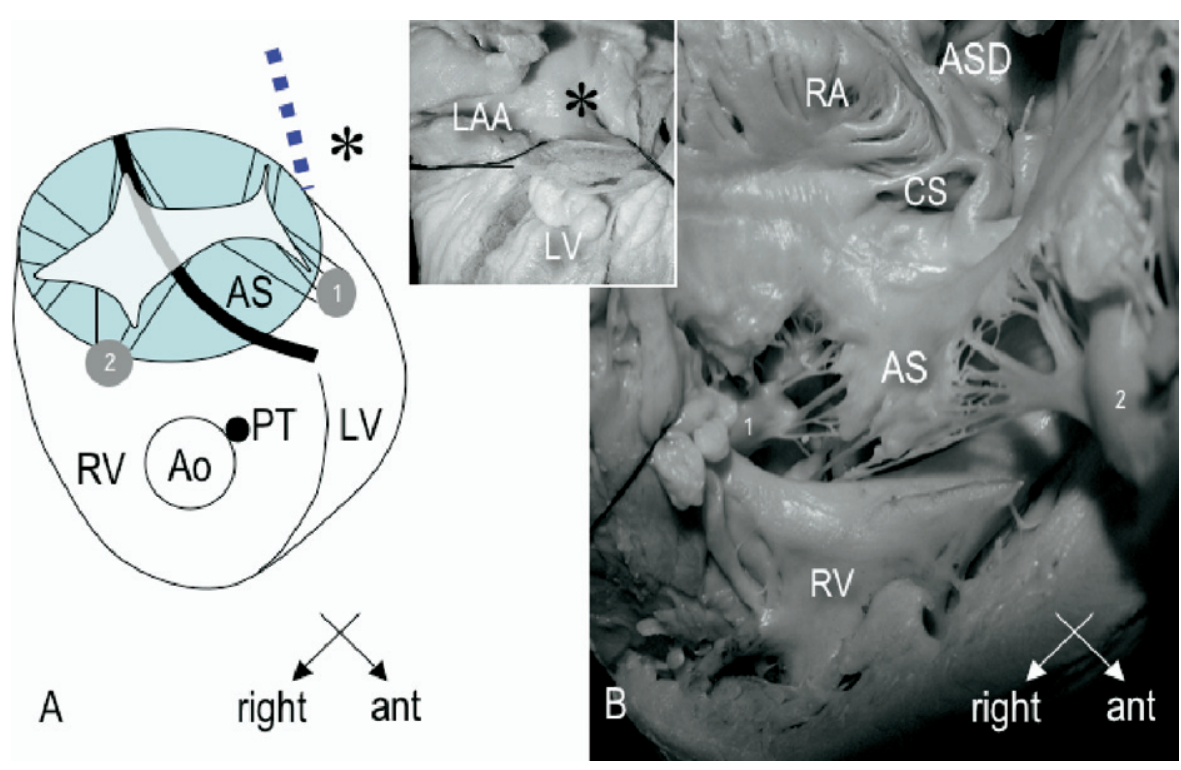

Figure E5. A, Segmental arrangement of specimen No. 14: absent left AV connection $\left({ }^{*}\right)$ with straddling right AV valve; right-hand topology of the ventricles; planes of the atrial (dotted line) and ventricular (black line) septums. Diagram corresponds in projection to its respective photograph. B, Free-floating anterosuperior bridging leaflet is attached by short, muscularized cords to a papillary muscle $(1,2)$ in either ventricle. Inset: Absent left AV connection $\left({ }^{*}\right)$ is represented by a dimple in the floor of the left atrium. Ao, Aorta; $A S D$, atrial septal defect; $C S$, coronary sinus; $L A$, left atrium; $L A A$, left atrial appendage; $L V$, left ventricle; $P T$, (atretic) pulmonary trunk; $R A$, right atrium; $R V$, right ventricle. 